\title{
Anatomia foliar de bromélias ocorrentes em áreas de cerrado do Estado de São Paulo, Brasil ${ }^{1}$
}

\author{
Suzana Lúcia Proença ${ }^{2,3}$ e Maria das Graças Sajo
}

Recebido em 20/07/2006. Aceito em 21/12/2006

\begin{abstract}
RESUMO - (Anatomia foliar de bromélias ocorrentes em áreas de cerrado do Estado de São Paulo, Brasil). Visando apontar características inerentes à família Bromeliaceae e indicar possíveis adaptações anatômicas encontradas nas espécies de cerrado, foram estudadas as folhas de cinco Bromelioideae, sete Tillandsioideae e uma Pitcairnioideae. Em geral, nas Bromelioideae, os estômatos estão aprofundados na epiderme e verifica-se um tecido mecânico epidérmico e subepidérmico; observa-se um tecido parenquimático armazenador de água, células esclerificadas não relacionadas aos tecidos vasculares, além de canais de aeração percorrendo longitudinalmente o mesofilo. Nas Tillandsioideae, as folhas são densamente recobertas por escamas, os estômatos ocorrem nas duas superfícies e o mesofilo é bastante compacto. Em Pitcairnioideae, a estrutura foliar é bastante semelhante à das Bromelioideae, embora os estômatos sejam ligeiramente elevados em relação à epiderme e não ocorram grupos de células esclerificadas extravasculares. Os resultados foram avaliados dentro de um contexto adaptativo e taxonômico.
\end{abstract}

Palavras-chave: Bromeliaceae, anatomia foliar, cerrado, Estado de São Paulo

\begin{abstract}
Leaf anatomy of bromeliads from the cerrado of São Paulo State, Brazil). Our aim was to indicate typical features of Bromeliaceae as well as possible adaptive features found in cerrado species. We studied the leaves of five Bromelioideae, seven Tillandsioideae and one Pitcairnoideae. Usually the stomata of Bromelioideae are located only on the abaxial leaf surface, there is epidermal and subepidermal mechanical tissue present, as well as water-storage parenchyma, sclerified cells not related to the vascular tissues, and longitudinal air canals. The leaves in Tillandsioideae are densely covered by peltate trichomes, and there are stomata on both surfaces and a compact mesophyll. In Pitcairnioideae, the leaf structure is very similar to that of the Bromelioideae but the stomata are slightly raised above epidermal cell level and there are no sclerified cell groups. The results were evaluated in an adaptive and taxonomic context.
\end{abstract}

Key words: Bromeliaceae, leaf anatomy, cerrado, São Paulo State

\section{Introdução}

A família Bromeliaceae, uma das mais representativas da flora neotropical, abrange cerca de 56 gêneros e 2.600 espécies epífitas ou terrestres (Smith \& Till 1998). Ocupa posição basal dentro de Poales (APG II 2003), junto com Typhaceae e Rapateaceae (Bremer 2002; Davis et al. 2004) e, tradicionalmente, tem sido dividida em três subfamílias: Pitcairnioideae, Tillandsioideae e Bromelioideae separadas, principalmente, pelo hábito de crescimento, tipo de tricoma, tipo de fruto e semente e pela posição do ovário (Smith \& Downs 1974; 1977; 1979). Análises moleculares recentes têm confirmado a monofilia de
Bromelioideae e Tillandsioideae, mas apontam Pitcairnioideae como um grupo polifilético (Crayn et al. 2000; Horres et al. 2000; Barfuss et al. 2005).

Muitas bromélias possuem metabolismo CAM (Metabolismo Ácido das Crassulaceae), característica que, junto com o hábito epífito, representam apomorfias para a família por serem raros ou ausentes nas outras Poales (Crayn et al. 2004). Segundo Crayn et al. (2004), as duas características surgiram independentemente e várias vezes durante a história evolutiva das subfamílias, sendo que em Bromelioideae, onde o epifitismo é considerado derivado, $90 \%$ das espécies apresentam fotossíntese CAM; já em Tillandsioideae, grupo predominantemente epifítico, o metabolismo

\footnotetext{
1 Parte da Tese de Doutorado da primeira Autora

2 Universidade Estadual Paulista, Instituto de Biociências, Departamento de Botânica, C. Postal 199, 13506-900 Rio Claro, SP, Brasil

3 Autor para correspondência: suzanaproenca@hotmail.com
} 
CAM aparece em todas as Tillandsia epífitas atmosféricas (Martin 1994), enquanto que em Pitcairnioideae, onde os representantes são terrestres, predomina o metabolismo $\mathrm{C}_{3}$

A estrutura foliar das Bromeliaceae vem sendo estudada com objetivos diversos. Tomlinson (1969), numa revisão anatômica abrangente, caracteriza cada uma das três subfamílias com base, especialmente, na estrutura das escamas foliares, dos estômatos e do mesofilo. Alguns trabalhos descrevem as folhas de certas espécies, como o de Billings (1904) com Tillandsia usneoides, o de Krauss (1949) com Ananas comosus e o de Braga (1977) com espécies de Ananas, Tillandsia, Vriesea, Aechmea e Streptocalix, presentes na campina amazônica. Outros utilizam a anatomia foliar no entendimento taxonômico de diferentes grupos, como o de Robinson (1969), que delimita as espécies de Connelia, Cottendorfia e Navia e o de Sajo et al. (1998), que analisam as folhas de 68 espécies pertencentes à Nidularium e gêneros afins, delimitando seis grupos distintos. Mais recentemente, destacam-se os trabalhos de Aoyama \& Sajo (2003), que separam as espécies de Aechmea, subgênero Lamprococcus; de Proença \& Sajo (2004), que apresentam uma chave de identificação para as Aechmea do estado de São Paulo; e o de Sousa et al. (2005), que separam as espécies de Aechmea, subgênero Chevaliera. Outros estudos têm como objetivo compreender a variabilidade adaptativa presente na família. É o caso do trabalho de Flores (1975) que compara a anatomia foliar de Aechmea mexicana Baker (espécie terrestre de regiões áridas) e Hechtia glomerata Zucc. (espécie epífita de florestas úmidas), de Brighigna et al. (1984) com Tillandsia de ambientes áridos e tropicais, e de Gómez \& Winkler (1991) com bromélias de ambientes salinos e de regiões externas ao mangue. Citam-se, ainda, os estudos de Souza \& Neves (1996), Arruda \& Costa (2003) e Scatena \& Segecin (2005) com espécies de Tillandsioideae, em que interpretam os caracteres observados nas folhas, como possíveis adaptações ao ambiente em que vivem as plantas e/ou ao hábito epifítico.

O cerrado apresenta um gradiente fisionômico que varia desde uma paisagem campestre (os campos limpos) até uma paisagem com aspecto florestal (os cerradões), intermediado pelos campos sujos, campos cerrados e cerrado sensu stricto (Coutinho 2002). A paisagem se complementa com as matas de galerias ao longo dos cursos d'água, que percorrem essas formações (Ribeiro \& Walter 1998). O cerrado caracteriza-se ainda, por apresentar marcada estação chuvosa e invernos frios e secos (Franco 2002). Nas diversas fisionomias que compõem o cerrado paulista é comum a ocorrência de bromélias epífitas e terrestres.

No Estado de São Paulo, a vegetação de cerrado cobre, atualmente, menos de $7 \%$ de sua área original e existe apenas na forma de fragmentos isolados (Durigan et al. 2003). No entanto, essas áreas apresentam características florísticas, de reprodução, de limitação ambiental, que garantem a sustentabilidade mesmo de pequenos fragmentos, o que é uma particularidade desse bioma, quando comparado com os demais biomas paulistas (Cavassan 2002).

$\mathrm{O}$ presente trabalho descreve a anatomia foliar de uma Pitcairnioideae, cinco Bromelioideae e sete Tillandsioideae, encontradas em remanescentes de cerrado do estado de São Paulo, visando apontar características inerentes à Bromeliaceae e indicar possíveis adaptações anatômicas encontradas nos representantes desse bioma.

\section{Material e métodos}

O material utilizado bem como o local de coleta e a fisionomia de cerrado encontram-se listados na Tab. 1. Todo o material foi identificado pela primeira autora e as exsicatas encontram-se depositadas no Herbário Rioclarense (HRCB).

As folhas foram fixadas em FAA 50 (Johansen 1940) e, posteriormente, transferidas para etanol $50 \%$. Para o estudo anatômico, secções transversais da porção mediana das lâminas foliares, obtidas à mão livre, foram submetidas ao processo de dupla coloração com safranina e azul de Astra (Bukatsch 1972; modificado apud Kraus \& Arduin 1997) e montadas em gelatina glicerinada (Kaiser 1880 apud Kraus \& Arduin 1997). Para este estudo foram utilizadas as folhas de dois a três indivíduos de cada espécie.

A análise da superfície foliar foi realizada com o uso de microscópio eletrônico de varredura (MEV). Para tanto, fragmentos da região mediana das folhas foram desidratados em série etílica crescente e submetidos ao ponto crítico com gás carbônico. Posteriormente, as amostras foram montadas em suportes metálicos e metalizadas com ouro.

Para os estudos histoquímicos, secções de material fresco foram submetidas ao Sudan IV, para evidenciar substâncias lipídicas (Gerlach 1984); ao floroglucinol em meio ácido, para evidenciar paredes lignificadas 
Tabela 1. Espécies de Bromeliaceae estudadas.

\begin{tabular}{|c|c|c|}
\hline Subfamília/Espécie & Localidade/fisionomia de cerrado & Coleção \\
\hline \multicolumn{3}{|l|}{ BROMELIOIDEAE } \\
\hline Acanthostachys strobilacea (Baker) L.B. Sm. & Reserva Biológica de Moji-Guaçu/cerrado & S.L. Proença 201 \\
\hline \multirow[t]{3}{*}{ Ananas ananassoides (Baker) L.B. Sm. } & Estação Experimental de Itirapina/campo sujo & S.L. Proença 192 \\
\hline & Área de Proteção Ambiental de Corumbataí/cerradão & S.L. Proença 205 \\
\hline & Universidade de São Paulo, Campus de Pirassununga/cerrado & S.L. Proença 214 \\
\hline Billbergia distachia (Vell.) Mez & Reserva Biológica de Moji-Guaçu/mata de galeria & S.L. Proença 208 \\
\hline B. porteana Brongn. & Reserva Biológica de Moji-Guaçu/cerrado e mata de galeria & S.L. Proença 198 \\
\hline \multirow[t]{2}{*}{ B. balansae $\mathrm{Mez}$} & Reserva Biológica de Moji-Guaçu/cerrado sujo & S.L. Proença 188 \\
\hline & Estação Experimental de Itirapina/campo & S.L. Proença 197 \\
\hline \multicolumn{3}{|l|}{ PITCAIRNIOIDEAE } \\
\hline \multirow[t]{2}{*}{ Dyckia tuberosa (Vell.) Beer } & Estação Experimental de Itirapina/campo sujo & S.L. Proença 196 \\
\hline & Universidade de São Paulo, Campus de Pirassununga/cerrado & S.L. Proença 213 \\
\hline \multicolumn{3}{|l|}{ TILLANDSIOIDEAE } \\
\hline Tillandsia loliacea Mart. ex Schult. f. & Área de Proteção Ambiental de Corumbataí/cerradão & S.L. Proença 202 \\
\hline \multirow{2}{*}{ T. pohliana $\mathrm{Mez}$} & Reserva Biológica de Moji-Guaçu/cerrado & S.L. Proença 186 \\
\hline & Pratânia/cerrado & S.L. Proença 216 \\
\hline \multirow[t]{3}{*}{ T. recurvata $(\mathrm{L}.) \mathrm{L}}$. & Reserva Biológica de Moji-Guaçu/mata de galeria & S.L. Proença 190 \\
\hline & Estação Experimental de Itirapina/mata de galeria & S.L. Proença 194 \\
\hline & Pratânia/cerrado & S.L. Proença 215 \\
\hline T. tenuifolia $\mathrm{L}$. & Reserva Biológica de Moji-Guaçu/mata de galeria & S.L. Proença 189 \\
\hline \multirow{2}{*}{ T. tricholepis Baker } & Estação Experimental de Itirapina/mata de galeria & S.L. Proença 195 \\
\hline & Área de Proteção Ambiental de Corumbataí/cerradão & S.L. Proença 204 \\
\hline T. usneoides (L.) L. & Estação Experimental de Itirapina/mata de galeria & S.L. Proença 193 \\
\hline Vriesea sp. & Estação Experimental de Itirapina/mata de galeria & S.L. Proença 217 \\
\hline
\end{tabular}

(Sass 1951); ao lugol, para confirmar a presença de amido ou compostos fenólicos (Johansen 1940); ao óleo de cravo e cristais de fenol, para confirmar a presença de sílica, nas células da epiderme (Johansen 1940); ao ácido clorídrico e ácido acético glacial a 10\%, para determinar a natureza química dos cristais (Chamberlain 1932, modificado apud Kraus \& Arduin 1997).

Os resultados foram documentados através de eletromicrografias e fotomicrografias. A lâmina com escala micrométrica foi fotografada nas mesmas condições.

\section{Resultados}

A maioria dos representantes estudados possui hábito epifítico, com exceção de Ananas ananassoides, Bromelia balansae e Dyckia tuberosa que são plantas terrestres. Das epífitas analisadas, apenas Vriesea sp. possui folhas com bainhas amplas formando rosetas que propiciam o acúmulo de água e detritos. A maior parte das espécies estudadas apresenta filotaxia espiralada, exceto por Tillandsia recurvata e Tillandsia usneoides, que possuem filotaxia dística e subdística, respectivamente.
As folhas, em vista frontal, exibem escamas revestindo as duas superfícies (Fig. 1-18, 22). Nas Bromelioideae e na Pitcairnioideae (D. tuberosa), as escamas ocorrem nos sulcos longitudinais, onde se distribuem em fileiras, nas duas superfícies foliares (Fig. 1-3, 7-9, 11, 12). Na maioria das Tillandsioideae (T. loliacea, T. pohliana, T. recurvata, T. tenuifolia, T. tricholepis, T. usneoides), as escamas se dispõem ao acaso (Fig. 4-6, 13-16) por toda a superfície da folha, apesar de em Vriesea sp. (Fig. 17) e em T. pohliana se distribuírem em fileiras longitudinais, na superfície abaxial.

Em vista frontal, observa-se apenas o escudo das escamas, que é constituído pelo disco central e pela ala (Fig. 1-18, 22). Nas espécies de Bromelioideae e Pitcairnioideae, a distinção entre as células do disco central e da ala não é perceptível (Fig. 1-3, 7-12). Nas Tillandsia, o disco é formado por quatro células centrais, circundadas por dois anéis celulares, sendo o interno constituído por oito células e denominado pericentral, e o externo formado por dezesseis células e chamado subperiférico (Fig. 5, 13, 15, 16). Na Tillandsioideae - Vriesea sp., observam-se quatro células centrais circundadas por dois anéis portadores de oito células cada (Fig. 18). Em todas as 
Tillandsioideae, a ala é composta por numerosas células periféricas, alongadas e dispostas radialmente (Fig. 4-6, 13-18).

Em alguns representantes, como em Billbergia distachia (Fig. 1, 10), T. pohliana (Fig. 4), A. ananassoides (Fig. 8), Bromelia balansae (Fig. 12), T. tenuifolia (Fig. 13), Vriesea sp. (Fig. 18), o escudo exibe um arranjo simétrico. Em outras ele é assimétrico, devido ao comprimento desigual das células da ala, como observado em $D$. tuberosa (Fig. 3), T. tricholepis (Fig. 5, 14), T. recurvata (Fig. 6, 15), T. usneoides (Fig. 16) e T. loliacea. Em Billbergia porteana, nota-se que as escamas da superfície adaxial (Fig. 2) são diferentes daquelas da superfície abaxial (Fig. 11), que exibem formato simétrico. Na maioria das folhas, as escamas cobrem completamente os estômatos (Fig. 7-16, 22, 23), sendo que nas Tillandsia as alas se sobrepõem completamente (Fig. 13-16). Entretanto, nas folhas de Vriesea sp., os estômatos encontram-se expostos, devido à menor quantidade de escamas (Fig. 17, 18).

As células epidérmicas possuem contorno retangular, em vista frontal, sendo que nas Tillandsioideae, suas paredes anticlinais são sinuosas em T. pohliana (Fig. 19), T. recurvata, T. tenuifolia e Vriesea sp., e onduladas em T. loliacea, T. tricholepis e T. usneoides. Na Pitcairnioideae e nas Bromelioideae, as paredes das células da epiderme são sinuosas.

Os estômatos se distribuem em sulcos ao longo das folhas, como observado na Pitcairnioideae (Fig. 20) e nas Bromelioideae - Bromelia balansae (Fig. 21), Billbergia porteana (Fig. 22), Ananas ananassoides, Billbergia distachia e Acanthostachys strobilacea ou se dispõem em fileiras longitudinais, como em Vriesea sp. (Fig.17) e T. pohliana. Exceto por Vriesea sp., com estômatos posicionados no mesmo nível das demais células da epiderme (Fig. 24) e por D. tuberosa, com estômatos posicionados acima das demais células epidérmicas (Fig. 20), essas estruturas localizam-se em nível inferior nas demais folhas estudadas (Fig. 21-23).

Em secção transversal, observa-se que as folhas apresentam epiderme unisseriada revestida por cutícula relativamente delgada. As células epidérmicas possuem paredes com grau de espessamento variável entre as espécies. Nas folhas de Bromelia balansae (Fig. 25), Billbergia distachia (Fig. 26), D. tuberosa (Fig. 27), Billbergia porteana (Fig. 30), T. tenuifolia (Fig. 38), T. pohliana (Fig. 41), Acanthostachys strobilacea e Ananas ananassoides, as células epidérmicas possuem paredes lignificadas e com espessamento acentuado nas faces anticlinais e periclinal interna, tornando o lúmen bastante reduzido. Em Vriesea sp. (Fig. 28, 37) as paredes das células epidérmicas são pouco espessadas, embora lignificadas, enquanto que em Tillandsia loliacea (Fig. 29, 39), T. recurvata (Fig. 40), T. tricholepis e T. usneoides são delgadas e celulósicas. Conforme também observado em vista frontal (Fig. 19, 20), é comum a presença de corpos silicosos esféricos no interior das células da epiderme (Fig. 25, 27). Em secção transversal, as escamas são constituídas por duas células basais, um pedículo e um escudo e ocorrem em ambas as superfícies das folhas, como observado em Billbergia porteana (Fig. 30), T. tenuifolia (Fig. 38) e T. loliacea (Fig. 39).

A maioria das folhas estudadas é hipoestomática, embora em T. loliacea (Fig. 39), T. recurvata, T. tricholepis e T. usneoides, as folhas sejam anfiestomáticas. Nas folhas de Bromelia balansae (Fig. 25, 33), Acanthostachys strobilacea (Fig. 31), Ananas ananassoides (Fig. 32), Billbergia porteana (Fig. 34) e D. tuberosa (Fig. 36), a superfície abaxial apresenta sulcos profundos originando regiões costais e intercostais, estando os estômatos alojados nas regiões intercostais. Como observado em vista frontal, nas folhas da maioria das espécies (Fig. 25, 26, 29, 33, $40,41)$, os estômatos estão aprofundados em maior ou menor grau na epiderme; nas de D. tuberosa (Fig. 27), as células-guarda se posicionam acima do nível das demais células epidérmicas, e nas folhas de Vriesea sp. (Fig. 28), as células-guarda se dispõem no mesmo nível das outras células da epiderme.

$\mathrm{Na}$ Pitcairnioideae e nas Bromelioideae, observa-se uma hipoderme mecânica formada por 1-4 camadas de células (Fig. 25-27, 30-36), em ambas as faces foliares. Nas folhas estudadas, é comum a presença de uma hipoderme aqüífera formada por células aclorofiladas e de paredes delgadas. Este tecido aparece na região adaxial das folhas de Bromelioideae (Fig. 31-35), de Pitcairnioideae (Fig. 36) e de algumas Tillandsioideae (T. tenuifolia - Fig. 38 e T. pohliana Fig. 41), e aparece adjacente à epiderme, nas duas faces das folhas de Vriesea sp. - Tillandsioideae (Fig. 37). As primeiras camadas de células da hipoderme aquíf́era são constituídas por células arredondadas e as camadas subjacentes por células alongadas anticlinalmente, como observado em Acanthostachys strobilacea (Fig. 31), Ananas ananassoides (Fig. 32), Bromelia balansae (Fig. 33), Billbergia porteana (Fig. 34), Billbergia distachia (Fig. 35), D. tuberosa (Fig. 36), T. tenuifolia (Fig. 38) 

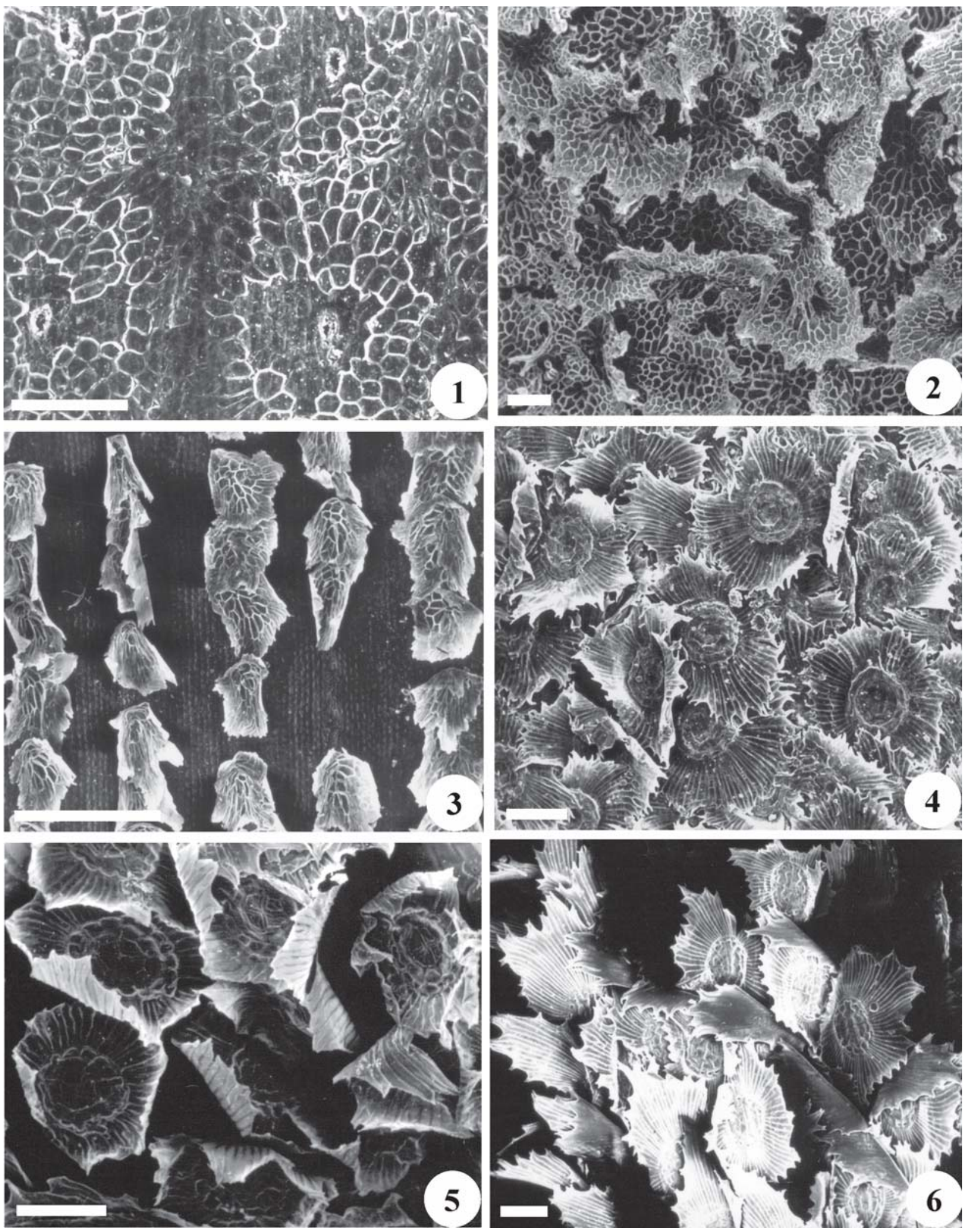

Figuras 1-6. Vista frontal da superfície foliar adaxial. 1-3. Escamas distribuídas em fileiras longitudinais. 4-6. Escamas distribuídas ao acaso. 1. Billbergia distachia (Vell.) Mez. 2. Billbergia porteana Brongn. 3. Dyckia tuberosa (Vell.) Beer. 4. Tillandsia pohliana Mez. 5. Tillandsia tricholepis Baker. 6. Tillandsia recurvada (L.) L. Barras $=500 \mu \mathrm{m}$ (fig. 3); $100 \mu \mathrm{m}$ (fig. 1, 2, 4-6). 

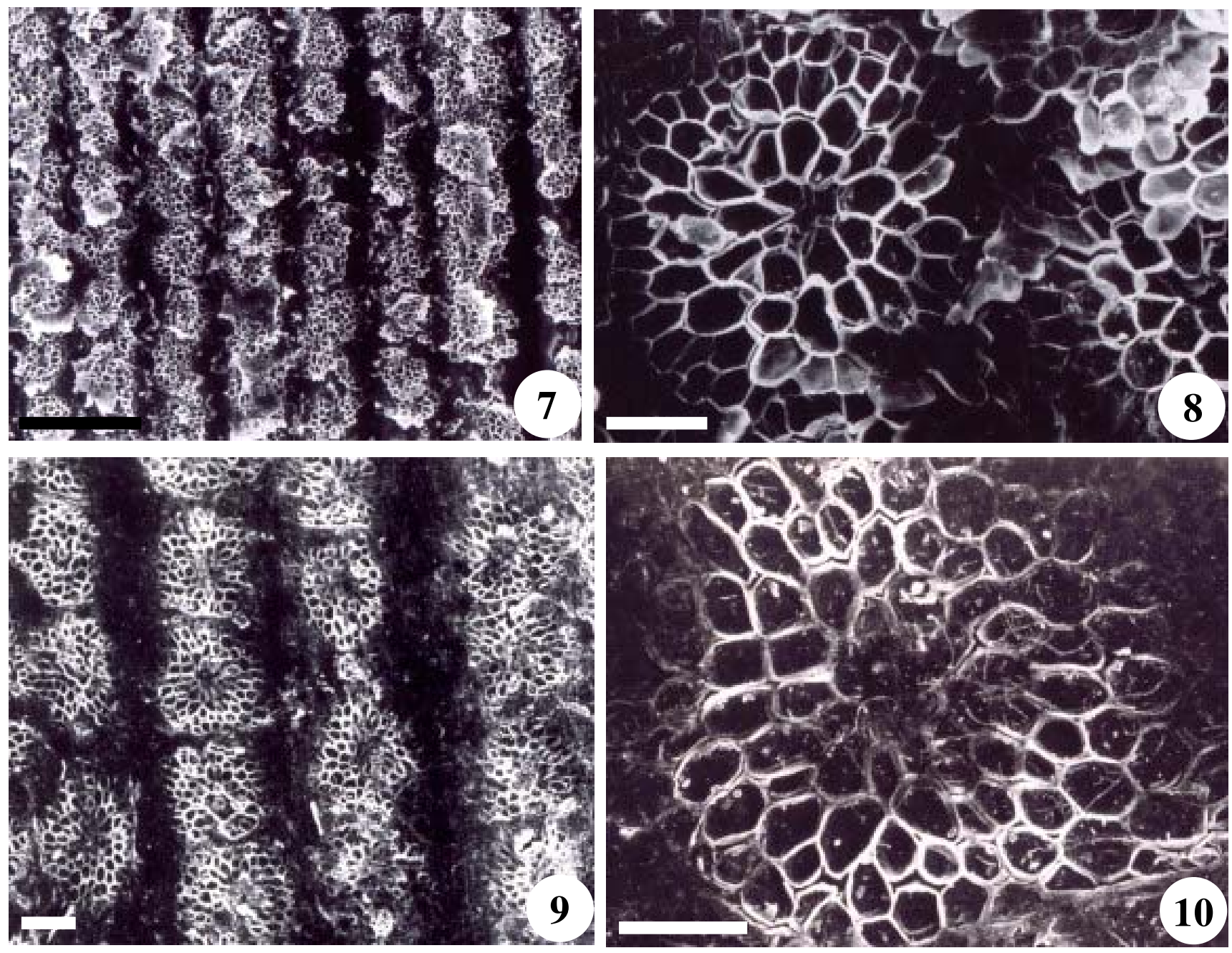

b\% $0 \%$ \%8\% \%

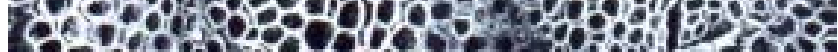

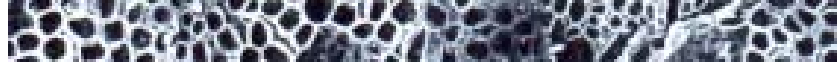

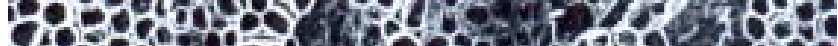

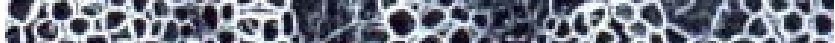

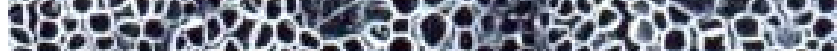

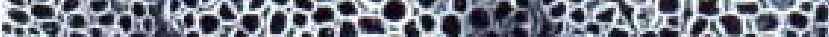
- 040 \%

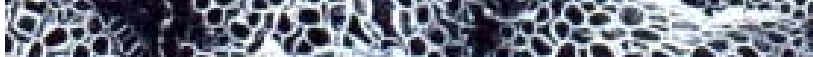

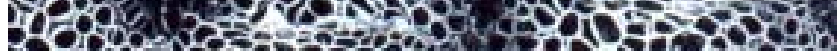

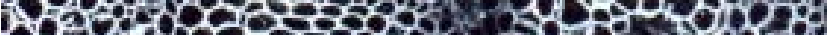
- 0 -

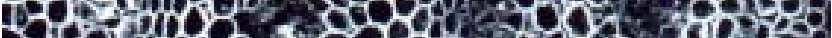

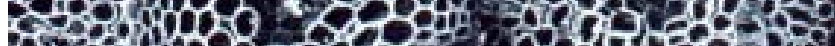

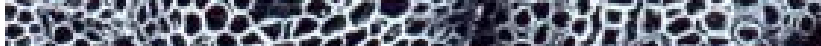

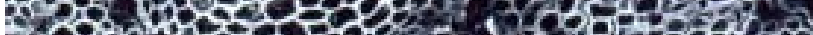

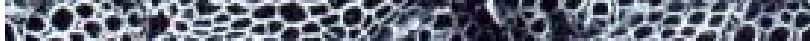

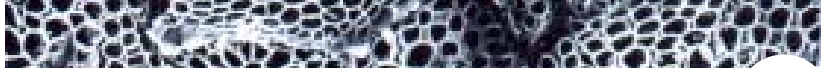

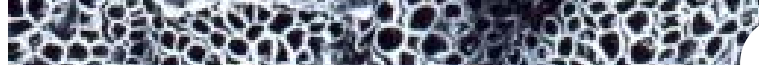

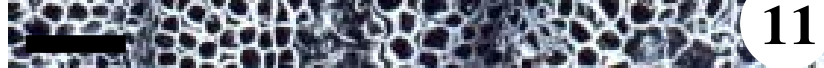

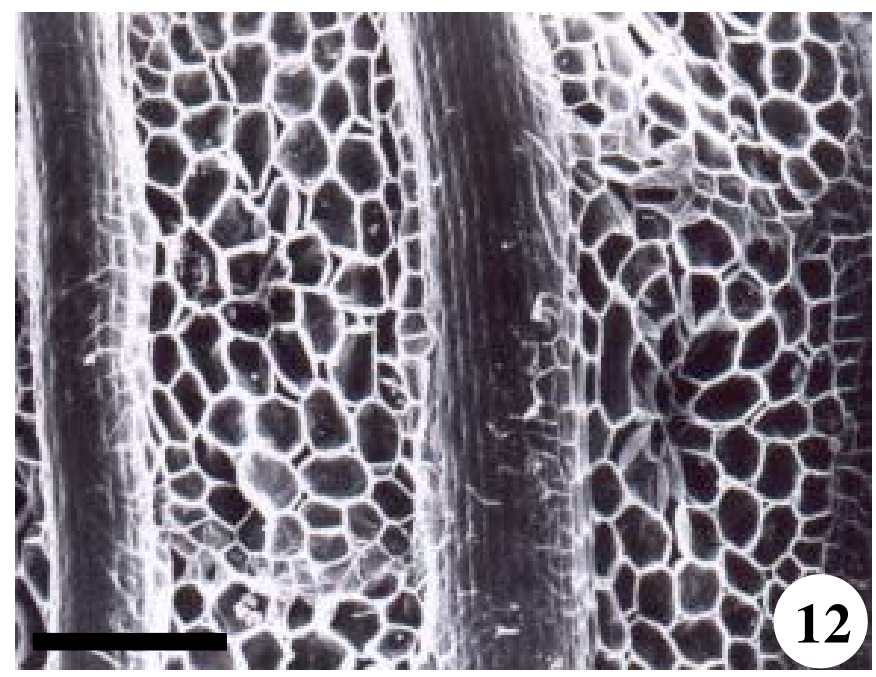

Figuras 7-12. Vista frontal da superfície abaxial de folhas de Bromelioideae, mostrando escamas distribuídas em fileiras longitudinais (fig. 7, 9, 11, 12). 7-8. Ananas ananassoides (Baker) L.B.Sm. 9-10. Billbergia distachia (Vell.) Mez. 11. Billbergia porteana Brongn. 12. Bromelia balansae Mez, mostrando escamas localizadas em sulcos. Barras = $500 \mu \mathrm{m}$ (fig. 7); $100 \mu \mathrm{m}$ (fig. 8, 9, 11, 12); $50 \mu \mathrm{m}$ (fig. 10). 

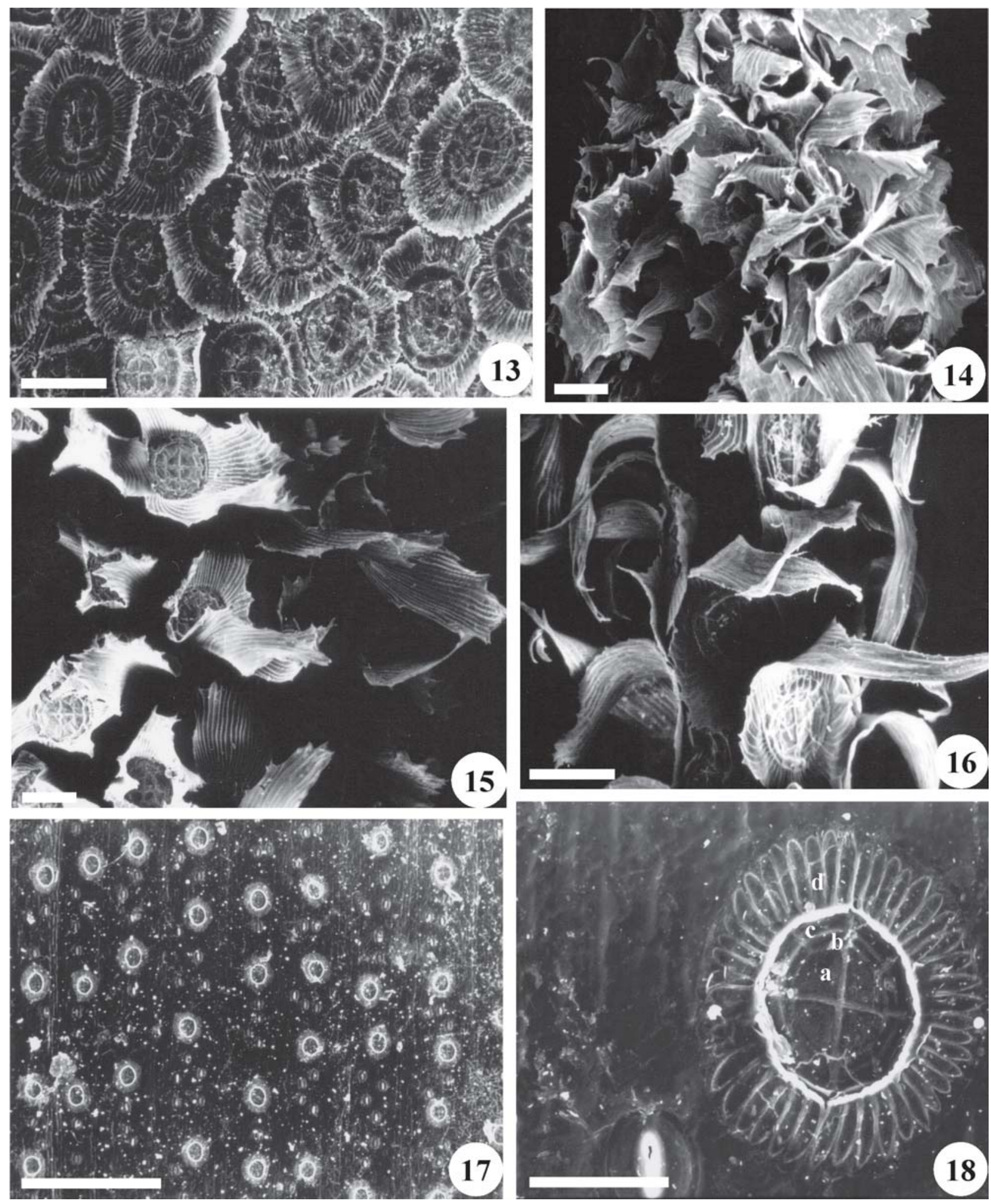

Figuras 13-18. Vista frontal da superfície abaxial de folhas de Tillandsioideae. 13-16. Escamas distribuídas ao acaso e sobrepostas. 17-18. Escamas distribuídas em fileiras. 13. Tillandsia tenuifolia L., com escamas simétricas. 14-16. Escamas assimétricas. 14. Tillandsia tricholepis Baker. 15. Tillandsia recurvata (L.) L. 16. Tillandsia usneoides (L.) L. 17-18. Vriesea sp., mostrando escamas simétricas. $a=$ células centrais. $b=$ células pericentrais. $c=$ células subperiféricas. $d=$ células periféricas. Barras $=500 \mu \mathrm{m}$ (fig. 17); $100 \mu \mathrm{m}$ (fig. 13-16); $50 \mu \mathrm{m}$ (fig. 18). 

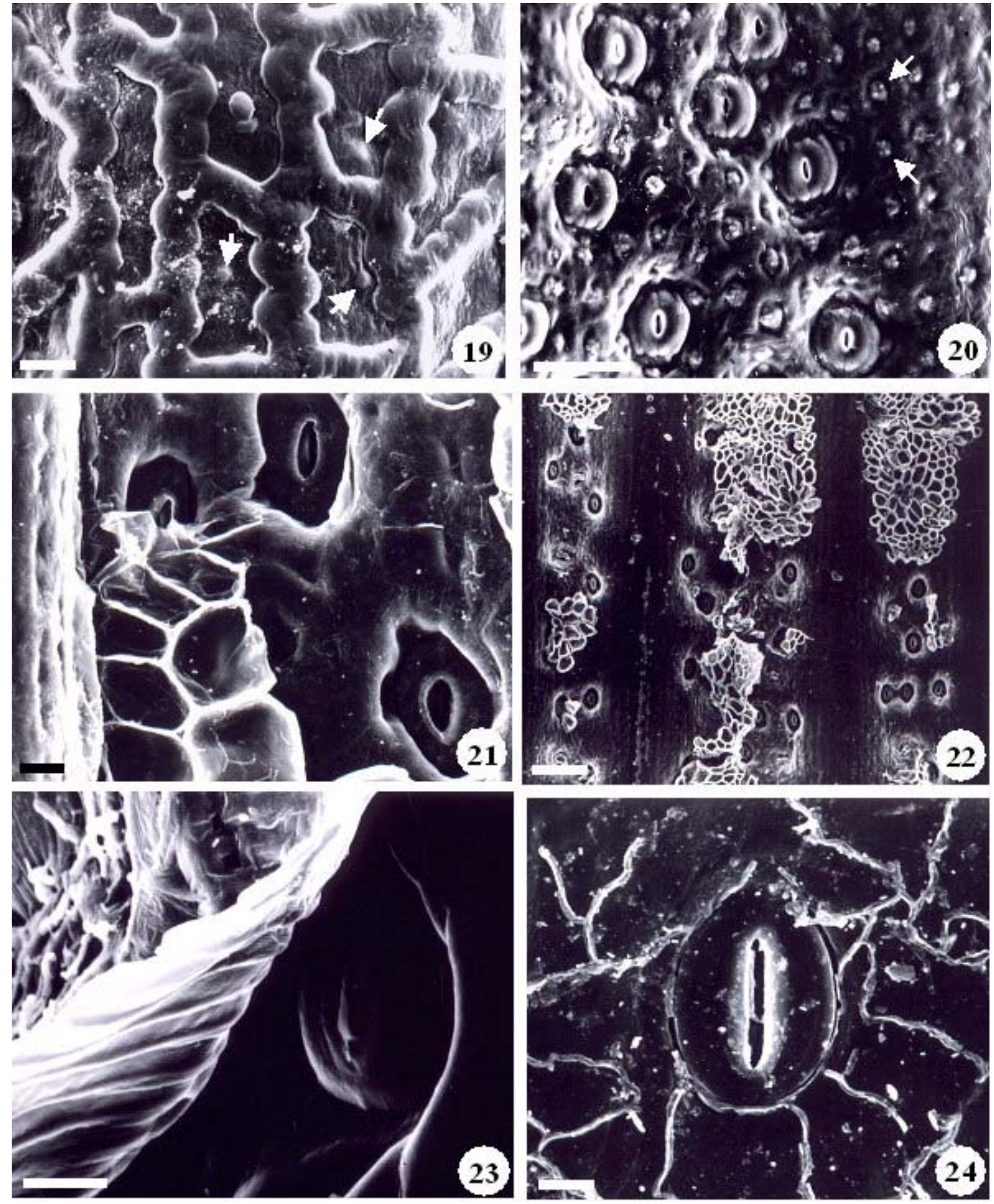

Figuras 19-24. Vista frontal de superfícies foliares. 19. Tillandsia pohliana Mez, mostrando células epidérmicas da superfície adaxial com paredes anticlinais sinuosas; as setas indicam corpo silicoso. 20-24. Superfície abaxial. 20. Dyckia tuberosa (Vell.) Beer, com estômatos posicionados acima do nível das demais células epidérmicas e localizados em sulco; as setas indicam corpo silicoso. 21-23. Estômatos aprofundados na epiderme. 21. Bromelia balansae Mez, com estômatos localizados em sulco. 22. Billbergia porteana Brongn., mostrando estômatos localizados em sulcos. 23. Tillandsia usneoides (L.) L. 24. Vriesea sp., com estômato posicionado no mesmo nível das demais células epidérmicas. Barras = $100 \mu \mathrm{m}$ (fig. 22); $50 \mu \mathrm{m}$ (fig. 20); $10 \mu \mathrm{m}$ (fig. 19, 21, 23, 24) 
e T. pohliana (Fig. 41), enquanto que em Vriesea sp. (Fig. 37) as células que constituem esse tecido são arredondadas. Nas folhas de T. loliacea (Fig. 39), T. recurvata (Fig. 40), T. tricholepis e T. usneoides não ocorre hipoderme aquífera; entretanto, nas três primeiras espécies, as células subepidérmicas da face adaxial são maiores que as outras do mesofilo e apresentam menos cloroplastos que as da face abaxial.

$\mathrm{Na}$ maioria das folhas estudadas, o parênquima clorofiliano é constituído por células arredondadas (Fig. 31-36, 38-41) e por células braciformes (Fig. 33, $35,37,41$ ), que podem ser alongadas (Vriesea sp. Fig. 37, A. strobilacea, B. distachia, D. tuberosa, T. tenuifolia e T. pohliana), estreladas (Bromelia balansae - Fig. 33, Ananas ananassoides) ou isodiamétricas, com projeções curtas, o que representa grande parte do clorênquima, em Billbergia porteana (Fig. 34). Em Bromelia balansae (Fig. 33) e Billbergia distachia (Fig. 35), o parênquima clorofiliano subjacente à hipoderme aqüífera, é constituído por células dispostas em paliçada. O mesofilo das Bromelioideae (Fig. 31-35), da Pitcairnioideae (Fig. 36) e de certas Tillandsioideae (Vriesea sp. - Fig. 37, T. tenuifolia - Fig. 38 e T. pohliana - Fig. 41), apresenta canais longitudinais de aeração situados entre os feixes vasculares. Esses canais são contíguos às câmaras subestomáticas (Fig. 33, 35, 37, 41) e atravessados por diafragmas formados por células braciformes (Fig. 33, 35, 37, 41). Em T. loliacea (Fig. 39), T. recurvata (Fig. 40), T. tricholepis e T. usneoides, o mesofilo é homogêneo e compacto, constituído por células de contorno arredondado, algumas vezes elíptico, e com pequenos espaços intercelulares.

Nas folhas de Acanthostachys strobilacea (Fig. 31), Ananas ananassoides (Fig. 32), Billbergia
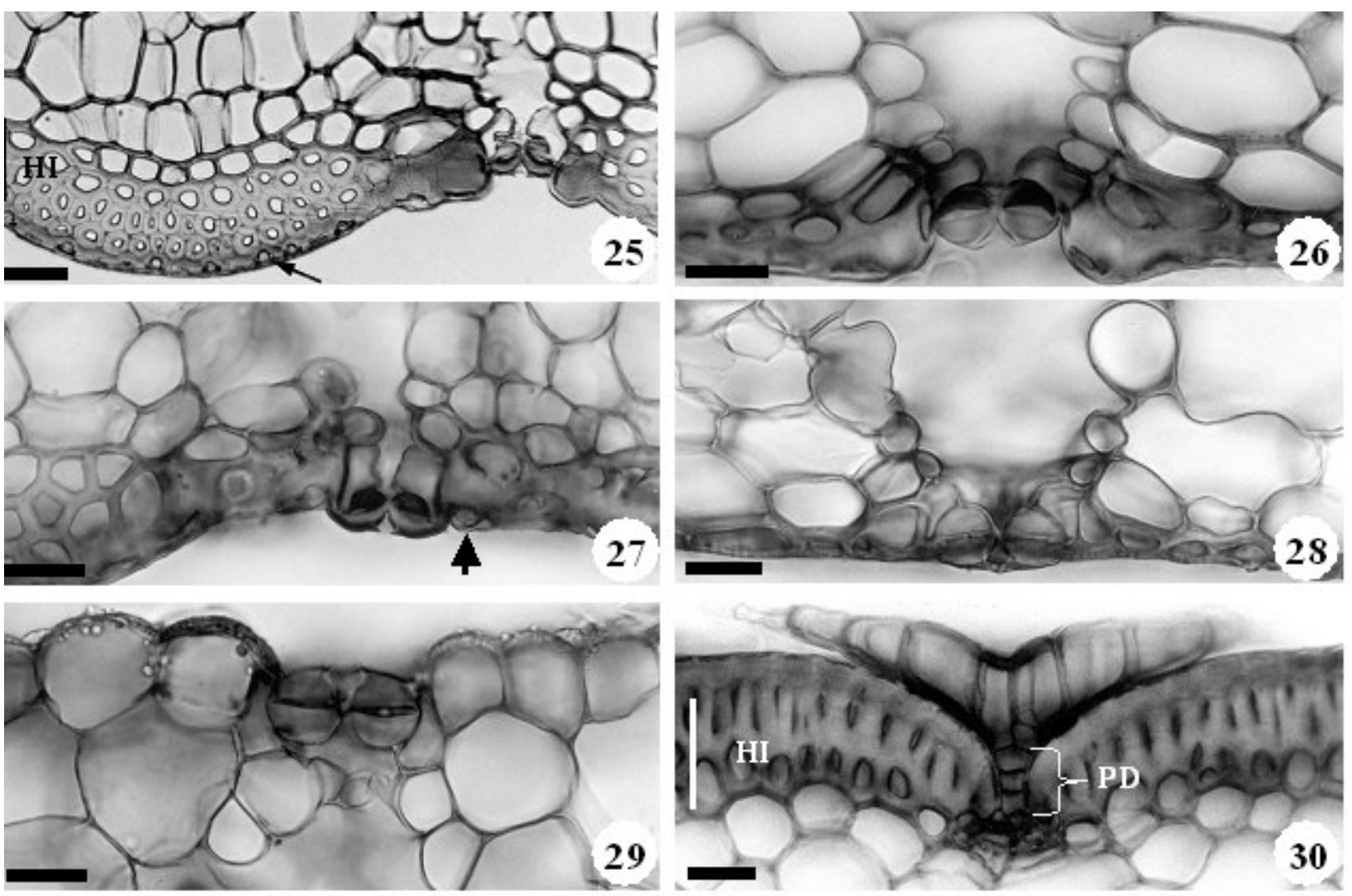

Figuras 25-30. Secções transversais de lâmina foliar. 25-28. Face abaxial. 29-30. Face adaxial. 25. Bromelia balansae Mez, mostrando estômato aprofundado na epiderme; a seta indica corpo silicoso na célula epidérmica. 26. Billbergia distachia (Vell.) Mez, estômato aprofundado na epiderme. 27. Dyckia tuberosa (Vell.) Beer, mostrando células-guarda posicionadas acima das demais células da epiderme; a seta aponta corpo silicoso. 28. Vriesea sp., com estômato posicionado no mesmo nível das outras células epidérmicas. 29. Tillandsia loliacea Mart. ex Schult. f., estômato posicionado em nível inferior ao das demais células epidérmicas. 30. Billbergia porteana Brongn., mostrando escama. $\mathrm{HI}=$ hipoderme mecânica. $\mathrm{PD}=$ pedículo da escama. Barras = $30 \mu \mathrm{m}$ (fig. 25, 30); $20 \mu \mathrm{m}$ (fig. 26, 27-29). 


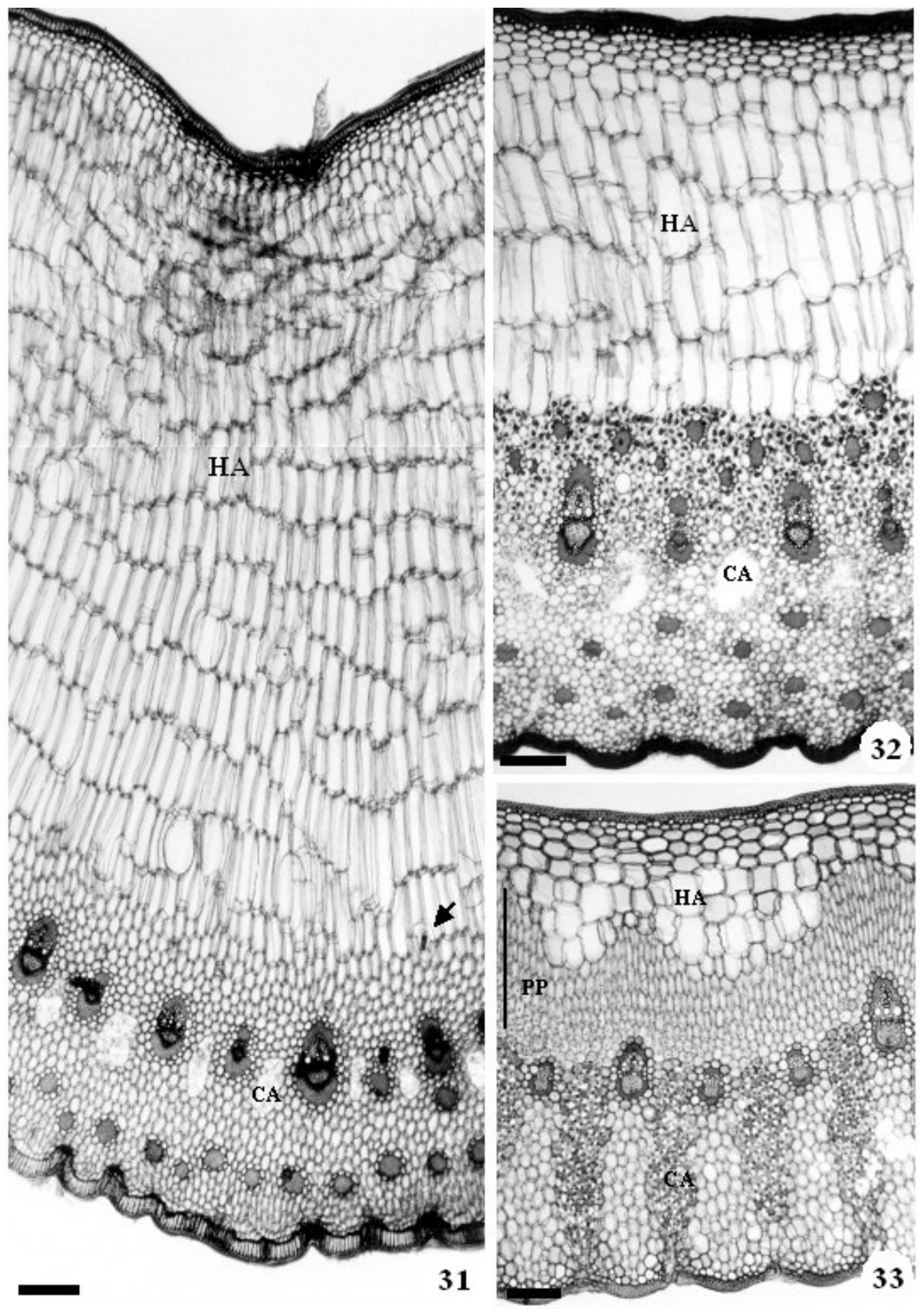

Figuras 31-33. Secções transversais de lâmina foliar. 31. Acanthostachys strobilacea (Baker) L.B.Sm., mostrando canais de aeração alternados com feixes vasculares e grupos de fibras extravasculares na face abaxial; a seta indica idioblasto de ráfides. 32. Ananas ananassoides (Baker) L.B.Sm., com grupos de fibras extravasculares por todo o parênquima clorofiliano. 33. Bromelia balansae Mez, mostrando canais de aeração atravessados por diafragmas constituídos por células estreladas, contínuos com as câmaras subestomáticas. $\mathrm{HA}=$ hipoderme aquíifera. $\mathrm{PP}=$ parênquima paliçádico. $\mathrm{CA}=$ canal de aeração. Barras = $200 \mu \mathrm{m}$ (fïg. 31-33). 

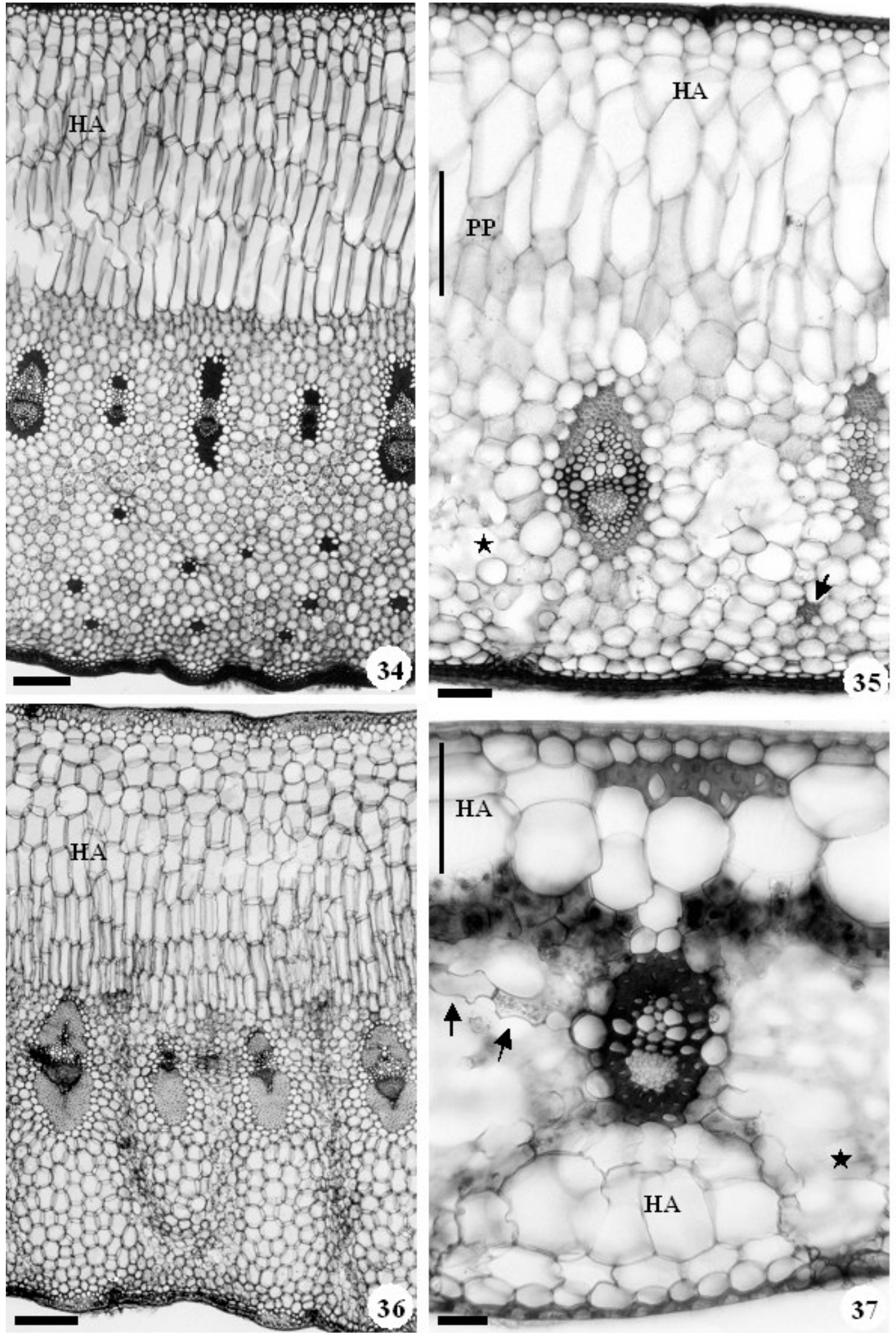

Figuras 34-37. Secções transversais de lâmina foliar. 34. Billbergia porteana Brongn. 35. Billbergia distachia (Vell.) Mez, mostrando grupo de fibra extravascular (seta) e canal de aeração com células braciformes, contínuo com a câmara subestomática (estrela). 36. Dyckia tuberosa (Vell.) Mez. 37. Vriesea sp., mostrando grupo de fibras extravasculares localizado na face adaxial do mesofilo e canal de aeração contínuo à câmara subestomática (estrela); as setas indicam células braciformes alongadas. HA = hipoderme aquiífera. $\mathrm{PP}=$ parênquima paliçádico. Barras = $200 \mu \mathrm{m}$ (fig. 34, 36); $70 \mu \mathrm{m}$ (fig. 35); $30 \mu \mathrm{m}$ (fig. 37). 
porteana (Fig. 34), Billbergia distachia (Fig. 35) e Vriesea sp. (Fig. 37), observam-se grupos de fibras não associados aos feixes vasculares. No mesofilo de Acanthostachys strobilacea, Billbergia porteana e Billbergia distachia estão presentes na face abaxial e são lignificados (Fig. 31, 34, 35), em Vriesea sp. esses grupos de fibras aparecem na face adaxial, próximo à epiderme e também são lignificados (Fig. 37). Já em Ananas ananassoides, os grupos de fibras estão dispersos no parênquima clorofiliano, em ambas as
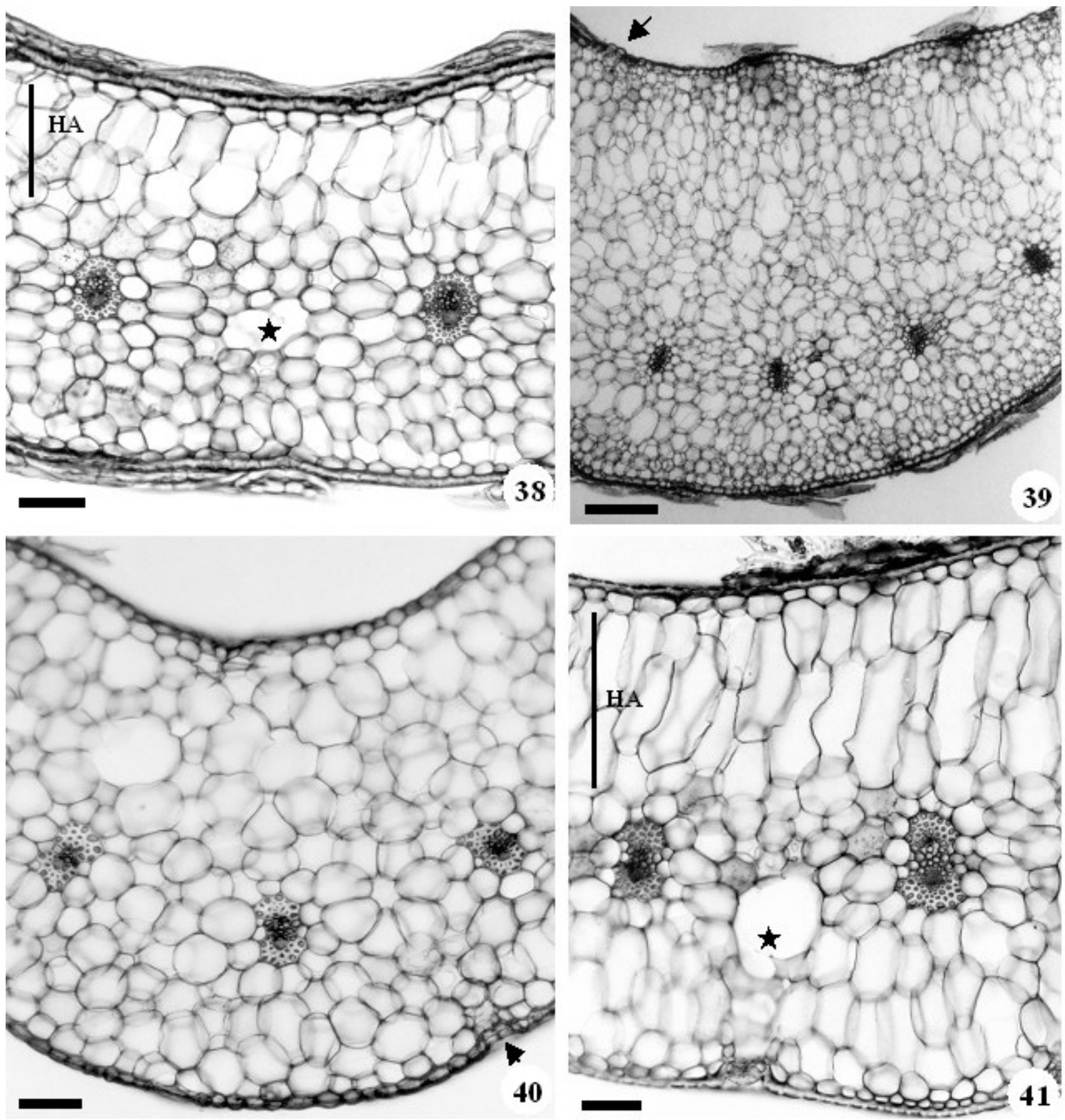

Figuras 38-41. Secções transversais de lâmina foliar. 38. Tillandsia tenuifolia L., mostrando canal de aeração (estrela) situado entre os feixes vasculares. 39. Tillandsia loliacea Mart. ex Schult. f., com mesofilo compacto e estômato na superfície adaxial (seta). 40. Tillandsia recurvata (L.) L., mostrando mesofilo homogêneo e estômato (seta). 41. Tillandsia pohliana Mez, onde se observa canal de aeração (estrela) contínuo à câmara subestomática. HA = hipoderme aqüífera. Barras = $200 \mu \mathrm{m}$ (fig. 39); $70 \mu \mathrm{m}$ (fig. 38, 40, 41). 
faces foliares (Fig. 32), e apresentam paredes espessadas, mas nem sempre lignificadas.

Os feixes vasculares são colaterais e se dispõem numa única série ao longo das lâminas. Geralmente, os feixes maiores se alternam com os menores e são circundados por 1-3 camadas de fibras pericíclicas, cujas paredes são espessadas e lignificadas, exceto em Ananas ananassoides (Fig. 32) e T. tricholepis, onde essas células possuem paredes espessadas, mas não totalmente lignificadas. Os feixes menores também podem ser totalmente envolvidos por fibras (completamente lignificadas ou não) (Fig. 33, 38, 40, 41) ou apresentar fibras adjacentes ao xilema e floema (Fig. 31, 32, 34-36). A camada de células parenquimáticas mais interna do mesofilo e que circunda as fibras pericíclicas representa a endoderme.

Idioblastos contendo ráfides de oxalato de cálcio são observados com freqüência na hipoderme aqüífera (Fig. 31) e no parênquima clorofiliano de todas as espécies, sendo particularmente abundante em Bromelia balansae. Nas folhas de Acanthostachys strobilacea, verifica-se a presença de grãos de amido por todo o parênquima clorofiliano.

\section{Discussão}

Dentre as espécies estudadas, as Tillandsioideae e três das Bromelioideae (Billbergia distachia, Billbergia porteana e Acanthostachys strobilacea) apresentam hábito epifítico e são encontradas em cerrado, cerradão e mata de galeria. As demais Bromelioideae (Ananas ananassoides e Bromelia balansae) e a Pitcairnioideae (Dyckia tuberosa) são terrestres e ocorrem em campo sujo e cerrado, onde ficam expostas à luminosidade, ou em cerradão, onde vivem à sombra da copa das árvores. Apesar dos diferentes hábitats, folhas provenientes de áreas campestres (mais iluminadas) são estruturalmente semelhantes àquelas de áreas florestais (mais sombreadas).

A maioria das folhas aqui estudadas exibe, em vista frontal, células epidérmicas com paredes anticlinais sinuosas que, de acordo com Krauss (1949), aumentam a superfície de contato entre as células, conferindo uma maior resistência ao tecido epidérmico, durante as possíveis expansões e contrações foliares decorrentes da variação no turgor.

As escamas foliares exibem as mesmas características descritas por Tomlinson (1969) e Strehl (1983) para vários representantes da família. Nas Tillandsioideae estudadas, observam-se claramente quatro células centrais do disco, circundadas por dois anéis de células, além de uma ala periférica formada por células alongadas. Já nas Bromelioideae e na Pitcairnioideae, a distinção entre o disco e a ala não é evidente. De acordo com Varadarajan \& Gilmartin (1987), as escamas de Bromelioideae apresentam quatro células centrais, porém nas de Pitcairnioideae o número de células centrais varia de um a quatro.

Em todas as Bromelioideae e na Pitcairnioideae estudadas, as escamas se distribuem em fileiras longitudinais, nas duas superfícies foliares. Em Vriesea sp. (Tillandsioideae) as escamas são ordenadas em fileiras longitudinais na superfície abaxial das folhas e distribuem-se de forma aleatória na superfície adaxial. Nas demais Tillandsioideae estudadas, as escamas exibem distribuição irregular em ambas as superfícies. De acordo com Strehl (1983), na maioria das espécies de Vriesea e de Tillandsia, as escamas apresentamse irregularmente distribuídas nas duas superfícies foliares. A mesma autora sugere que a disposição das escamas em fileiras, seja um caráter plesiomórfico para Bromeliaceae, característica observada na Pitcairnioideae e nas Bromelioideae aqui analisadas. Strehl (1983) menciona que, em Bromelioideae, o formato do escudo das escamas é bastante variável, já que numa mesma espécie e numa mesma folha pode-se encontrar escamas diferentes, como observado aqui para Billbergia porteana. Vale salientar ainda que, nas espécies atmosféricas extremas como $T$. loliacea, $T$. recurvata, $T$. tricholepis e T. usneoides, as escamas se sobrepõem e exibem escudos com um prolongamento assimétrico lateral que, segundo Strehl (1983), é uma característica de grupos mais evoluídos e constitui uma apomorfia para Bromeliaceae. Esse prolongamento assimétrico dos escudos amplia a área superficial das escamas, aumentando assim a absorção de água e nutrientes nela dissolvidos, que estão disponíveis na atmosfera na forma de orvalho e chuva. Os tricomas peltados, considerados uma sinapomorfia para Bromeliaceae (Gilmartin \& Brown 1987), exercem funções diversas como absorver água e minerais (Tomlinson 1969), refletir a radiação solar, reduzir a transpiração e atrair polinizadores e dispersores de sementes (Benzing 2000).

Como em outros representantes da família (Tomlinson 1969; Krauss 1949; Souza \& Neves 1994; Sajo et al. 1998; Aoyama \& Sajo; Proença \& Sajo 2004; Scatena \& Segecin 2005; Sousa et al. 2005), observam-se nas folhas aqui estudadas, corpos silicosos no interior das células epidérmicas. Essas estruturas 
têm sido associadas com a resistência da planta ao ataque de insetos e fungos, por serem indigestas, e com a redução da transpiração, por serem altamente refrativas (Krauss 1949; Yoshida et al. 1962). Corpos silicosos também aparecem em outros representantes de Poales (APG II 2003), como Rapateaceae, Poaceae, Cyperaceae, Thurniaceae, Ecdeiocoleaceae e Centrolepidaceae (Dahlgren et al. 1985), indicando que esse caráter seja uma plesiomorfia para a ordem.

$\mathrm{Na}$ Pitcairnioideae e na maioria das Bromelioideae (Acanthostachy strobilacea, Ananas ananassoides, Billbergia porteana, Bromelia balansae), as folhas se caracterizam por apresentar superfície abaxial com regiões costais e intercostais bem demarcadas, com os estômatos alojados nas regiões intercostais. Essa localização particular dos estômatos provavelmente evita o excesso de transpiração, considerando-se que tais espécies ocorrem em áreas bem iluminadas. $\mathrm{Na}$ maior parte das espécies estudadas, os estômatos encontram-se restritos à superfície abaxial das folhas, apesar de T. recurvata, T. tricholepis, T. usneoides e T. loliacea possuírem folhas anfiestomáticas. Dessa forma, a ocorrência de estômatos nas duas superfícies foliares que, segundo Fahn \& Cutler (1992) aumenta a condutância do $\mathrm{CO}_{2}$ no mesofilo, provavelmente seja uma característica mais freqüente para as Tillandsia atmosféricas extremas.

Dentro de Bromeliaceae, a posição das célulasguarda é um caráter variável entre as espécies, como pode ser verificado pelos resultados de Krauss (1949), Tomlinson (1969), Braga (1977), Sajo et al. (1998), Aoyama \& Sajo (2003), Arruda \& Costa (2003), Proença \& Sajo (2004), Scatena \& Segecin (2005) e Sousa et al. (2005). Na maioria das espécies aqui estudadas, os estômatos aparecem aprofundados na epiderme, porém nas folhas de Vriesea sp., as célulasguarda estão posicionadas no mesmo nível das outras células, como também observado por Arruda \& Costa (2003) em espécies de Vriesea de ambientes xéricos e mésicos; e nas folhas de $D$. tuberosa, as célulasguarda ocupam posição superior à das demais células epidérmicas, conforme relatado por Pita (1997) para outras espécies do mesmo gênero encontradas em campos rupestres. No presente estudo, considera-se que a posição das células-guarda dentro da espécie seja um caráter fixo, pois indivíduos coletados em diferentes fisionomias de cerrado como campo sujo, cerrado, cerradão e mata de galeria apresentam folhas com estômatos numa mesma posição.

A hipoderme aqüífera encontrada nas folhas das Bromelioideae, de algumas Tillandsioideae
(T. pohliana, T. tenuifolia, Vriesea sp.) e da Pitcairnioideae, é formada por células parenquimáticas destituídas de cloroplastos. Embora esse tecido seja, em geral, pouco desenvolvido em Tillandsioideae (Tietze 1906 apud Tomlinson 1969), nas folhas de T. tenuifolia, T. pohliana e Vriesea sp. ocupa parte considerável do mesofilo. Já nas folhas de $T$. recurvata, $T$. tricholepis e $T$. loliacea não se observa um tecido aqüífero diferenciado, embora as células da região adaxial do mesofilo, sejam um pouco maiores e possuam menos cloroplastos que as do clorênquima abaxial, indicando um possível armazenamento de água, como sugerido por Medina (1974) para Tillandisa recurvata, e por Braga (1977) e Sajo et al. (1998) para outros representantes da família. A hipoderme aqüífera, de acordo com Brighigna et al. (1984), ao armazenar a água absorvida pelas escamas, protege a região clorofiliana da intensa luminosidade, além de favorecer o processo fotossintético.

Com relação ao parênquima clorofiliano, as folhas de Bromelia balansae e Billbergia distachia diferem estruturalmente das demais espécies estudadas pela presença de camadas de células em paliçada. Autores como Downs (1974), Arruda \& Costa (2003) e Proença \& Sajo (2004) fazem referência à presença de parênquima paliçádico nas espécies por eles estudadas. Entretanto, Downs (1974) sugere que essa característica não seja freqüente em Bromeliaceae.

Canais de aeração, dispostos longitudinalmente nas lâminas, são comuns nas folhas estudadas. Tais canais encontram-se conectados às câmaras subestomáticas e são, ocasionalmente, atravessados por diafragmas constituídos por células braciformes. Essa conexão entre os canais e as câmaras subestomáticas permite uma maior circulação de gases no interior das lâminas, além de conferir maior flexibilidade às folhas (Mauseth 1988). As células braciformes que atravessam os canais de aeração podem ser estreladas, alongadas ou isodiamétricas, dependendo da espécie considerada; tal variação também foi observada nas Aechmea dos subgêneros Lamprococcus (Aoyama \& Sajo 2003) e Chevaliera (Sousa et al. 2005).

Nas folhas de algumas Bromelioideae (Acanthostachys strobilacea, Ananas ananassoides, Billbergia porteana, Bromelia balansae) e da Pitcairnioideae, observam-se células de paredes espessas e lignificadas, na epiderme e hipoderme, além de fibras perivasculares e extravasculares (estas ausentes em Bromelia balansae e Dyckia tuberosa). Essas estruturas, não 
só aumentam a rigidez foliar oferecendo sustentação mecânica por ocasião de ventos fortes, como agem na proteção do mesofilo durante possíveis estresses hídrico e de temperatura, conforme descrito por Krauss (1949), Pyykkö (1966) e Brighigna et al. (1984) para as folhas de Bromeliaceae e de outras famílias de angiospermas.

Dentro de Tillandsioideae, somente as folhas de Vriesea sp. apresentam grupos de fibras extravasculares, na face adaxial do mesofilo, próximos à epiderme, como observado nas espécies de Vriesea estudadas por Braga (1977) e Arruda \& Costa (2003). Nas folhas das Tillandsia não se observam grupos de fibras extravasculares, conforme descrito por Tomlinson (1969), Souza \& Neves (1996) e Scatena \& Segecin (2005) para outras espécies do gênero. Nas Bromelioideae, todas as folhas apresentam esses grupos de fibras, com exceção de Bromelia balansae. Em Acanthostachys strobilacea, Billbergia distachia e Billbergia porteana, os grupos aparecem na face abaxial do parênquima clorofiliano enquanto que em Ananas ananassoides eles também estão presentes na face adaxial do mesofilo. A ocorrência de grupos de fibras extravasculares nas folhas das Bromelioideae, tem sido relatada por diversos autores (Krauss 1949; Tomlinson 1969; Braga 1977; Sajo et al. 1998; Aoyama \& Sajo 2003; Proença \& Sajo 2004; Sousa et al. 2005), que também observaram variação na distribuição dessas fibras nos mesofilos. Em Dyckia tuberosa não aparecem fibras extravasculares, conforme observado por Pita (1997) em representantes do mesmo gênero e de Encholirium, ambos pertencentes à Pitcairnioideae. Portanto, grupos de fibras extravasculares parecem estar ausentes em Pitcairnioideae e serem raros em Tillandsioideae, embora ocorram com freqüência nas folhas das Bromelioideae. Isto pode indicar que tal caráter encontra-se associado a grupos taxonômicos específicos dentro de Bromeliaceae, não tendo qualquer significado adaptativo para ambientes de cerrado. $\mathrm{O}$ mesmo pode-se dizer do caráter hipoderme mecânica, presente apenas nas folhas de Bromelioideae e Pitcairnioideae.

Idioblastos contendo ráfides de oxalato de cálcio, localizados no parênquima clorofiliano e na hipoderme aqüífera, são comuns nas folhas estudadas. A ocorrência desses cristais também é referida para Typhaceae - Typha e Sparganium (Dahlgren et al. 1985), considerada um grupo-irmão de Bromeliaceae em análises filogenéticas recentes (Bremer 2002; Davis et al. 2004). De acordo com Brighigna et al. (1984), a função do oxalato de cálcio é de neutralizar a grande quantidade de ácido oxálico produzido nas folhas das Tillandsia por eles estudadas. Esses cristais podem também representar formas de armazenamento de cálcio e de ácido oxálico, havendo possível reabsorção do oxalato de cálcio por ocasião da necessidade de cálcio (Sunell \& Healey 1979); podem, ainda, servir como depósitos para resíduos metabólicos que de outra forma seriam tóxicos para a célula ou tecido (Prychid \& Rudall 1999). Mauseth (1988) considera que as ráfides de oxalato de cálcio contribuam no sentido de tornar as plantas menos palatáveis aos herbívoros.

A partir das Poales ancestrais que, segundo Linder \& Rudall (2005), provavelmente cresciam em substratos úmidos e pobres em nutrientes, apenas metade das Bromeliaceae e poucas Rapateaceae escaparam da competição com outras plantas e dos locais temporariamente alagados, fixando-se sobre árvores e rochas e desenvolvendo, concomitantemente, uma série complexa de adaptações, que possibilitavam sua sobrevivência durante curtos períodos de estresse hídrico (Benzing 2000). Tais características adaptativas incluíam suculência, escamas foliares absorventes, roseta-tanque, além de metabolismo CAM (Benzing 2000). Linder \& Rudall (2005) mencionam que as plantas CAM fixam o $\mathrm{CO}_{2}$ durante a noite quando a perda de água é reduzida, e sugerem que o desenvolvimento desse metabolismo pré-adaptou essas linhagens a sobreviverem à baixa concentração de $\mathrm{CO}_{2}$ que caracterizou o Plioceno e o Pleistoceno.

Ao mesmo tempo em que as Bromeliaceae se fixaram sobre árvores e rochas, ambientes onde aparentemente as raízes se destinam mais à fixação do que à absorção (Benzing 2000), elas desenvolveram dois tipos de hábito de crescimento: num deles, as folhas possuem bainhas amplas e imbricadas, formando um tanque onde se acumulam água e detritos, que são absorvidos por escamas; no outro, as folhas são estreitas e densamente cobertas por escamas que absorvem água e nutrientes quando a superfície está úmida (Benzing et al. 1976; Benzing 2000).

Dentre os representantes epífitos estudados, somente Vriesea sp. (Tillandsioideae) possui folhas imbricadas com bainhas largas formando tanques. Nas Tillandsia (Tillandsioideae), as folhas são estreitas e densamente recobertas por escamas especializadas enquanto que nas Bromelioideae, também com folhas estreitas, as escamas são pouco diferenciadas. Nos representantes dessa última subfamília, sejam eles epifíticos ou terrestres, observam-se caracteres que podem representar adaptações a um estresse hídrico, 
tais como a presença de hipoderme mecânica e aquíf́era, a ocorrência de parênquima paliçádico e grupos de fibras extravasculares, além de estômatos aprofundados na epiderme. O mesmo pode-se dizer, a respeito da Pitcairnioideae - D. tuberosa, espécie terrestre que ocorre em ambientes bem iluminados e que apresenta hipoderme mecânica e aqüífera. Entretanto, é preciso lembrar que muitas das xeromorfias encontradas nas Bromeliaceae, embora possibilitem a exploração de ambientes extremos, representam adaptações ancestrais selecionadas durante a diversificação do grupo e não devem ser interpretadas apenas como caracteres relacionados a um ambiente particular onde elas vivem atualmente.

\section{Agradecimentos}

Ao Conselho Nacional de Desenvolvimento Científico e Tecnológico (CNPq), pela bolsa de Doutorado concedida à Suzana Lúcia Proença e pela bolsa de Produtividade em Pesquisa concedida à Maria das Graças Sajo; à Fundação de Amparo a Pesquisa do Estado de São Paulo (FAPESP), pelo auxílio concedido durante o desenvolvimento desta pesquisa.

\section{Referências bibliográficas}

Aoyama, E.M. \& Sajo, M.G. 2003. Estrutura foliar de Aechmea Ruiz \& Pav. subgênero Lamprococcus (Beer) Baker e espécies relacionadas (Bromeliaceae). Revista Brasileira de Botânica 26: 461-473.

APG (The Angiosperm Phylogeny Group). 2003. An update of the Angiosperm Phylogeny Group classification for the orders and families of flowering plants: APG II. Botanical Journal of the Linnean Society 141: 399-436.

Arruda, R.C.O. \& Costa, A.F. 2003. Foliar anatomy of five Vriesea Sect. Xiphion (Bromeliaceae) species. Selbyana 24: 180-189.

Barfuss, M.H.J.; Samuel, R.; Till, W. \& Stuessy, T.F. 2005. Phylogenetic relationships in subfamily Tillandsioideae (Bromeliaceae) based on DNA sequence data from seven plastid regions. American Journal of Botany 92: 337-351.

Benzing, D.H. 2000. Bromeliaceae: profile of an adaptative radiation. Cambridge, Cambridge University Press,

Benzing, D.H.; Henderson, K.; Kessel, B. \& Sulak, J. 1976. The absorptive capacities of bromeliad trichomes. American Journal of Botany 63: 1009-1014.

Billings, F.H. 1904. A study of Tillandsia usneoides. Botanical Gazette 38: 99-121.

Braga, M.M.N. 1977. Anatomia foliar de Bromeliaceae da Campina. Acta Amazonica 7: 1-74.
Bremer, K. 2002. Gondwanan evolution of the grass alliance of families (Poales). Evolution 56: 1374-1387.

Brighigna, L.; Fiordi, A.C. \& Palandri, M.R. 1984. Structural characteristics of mesophyll in some Tillandsia species. Phytomorphology 34: 191-200.

Cavassan, O. 2002. O cerrado do estado de São Paulo. Pp. 93-106. In: A.L. Klein (org.). Eugen Warming e o cerrado brasileiro: um século depois. Editora UNESP.

Coutinho, L.M. 2002. O bioma do cerrado. Pp. 77-91. In: A.L. Klein (org.). Eugen Warming e o cerrado brasileiro: um século depois. Editora UNESP.

Crayn, D.M.; Winter, K. \& Smith, A.C. 2004. Multiple origins of crassulacean acid metabolism and the epiphytic habit in the Neotropical family Bromeliaceae. Proceedings of the National Academy of Sciences 101: 3703-3708.

Crayn, D.M.; Randall, G.T.; Smith., J.A.C. \& Winter, K. 2000. Molecular systematics investigations in Pitcairnioideae (Bromeliaceae) as a basis for understanding the evolution of crassulacean acid metabolism (CAM). Pp. 569-579. In: K.L. Winter \& D.A. Morrison (eds.). Monocots: systematic and evolution. Melbourne, CSIRO.

Dahlgren, R.M.T.; Clifford, H.T. \& Yeo, P.F. 1985. The families of the monocotyledons: structure, evolution, and taxonomy. Berlin, Springer-Verlag.

Davis, J.I.; Stevenson, D.W.; Petersen, G.; Seberg, O.; Campbell, L.M.; Freudenstein, J.V.; Goldman, D.H.; Hardy, C.R.; Michelangeli, F.A.; Simmons, M.P.; Specht, C.D.; Vergara-Silva, F. \& Gandolfo, M. 2004. A phylogeny of the monocots, as inferred from rbcL and atpA sequence variation, and a comparison of methods for calculating jackknife and bootstrap values. Systematic of Botany 29: 467-510.

Downs, R.J. 1974. Anatomy and physiology. Pp. 2-28. In: L.B. Smith \& R.J. Downs (eds.). Pitcairnioideae (Bromeliaceae), Flora Neotropica. New York, Hafner Press.

Durigan, G.; Siqueira, M.F.; Franco, G.A.D.C.; Bridgewater, S. \& Ratter, J.A. 2003. The vegetation of priority áreas for cerrado conservation in São Paulo State, Brazil. Edinburgh Journal of Botany 60: 217-241.

Fahn, A. \& Cutler, D.F. 1992. Xerophytes. Pp.1-171. In: Encyclopedia of plant anatomy. Berlin, Gebrüder Borntraeger.

Flores, E.M. 1975. Algunos aspectos de anatomia foliar comparada de dos especies de Bromeliaceae (Aechmea mexicana Baker y Hechtia glomerata Zucc.). Revista de Biologia Tropical 23: 29-52.

Franco, A.C. 2002. Ecophysiology of woody plants. Pp. 178-197. In: P.S. Oliveira \& R.J. Marquis (eds.). The cerrados of Brazil. New York, Columbia University Press.

Gerlach, D. 1984. Botanische Mikrotechnik. Stuttgart, Georg Thieme Verlag.

Gilmartin, A.J. \& Brown, G.K. 1987. Bromeliales, related monocots, and resolution of relationships among Bromeliaceae subfamilies. Systematic Botany 12: 493-500. 
Gómez, M.A. \& Winkler, S. 1991. Bromelias en manglares del Pacífico da Guatemala. Revista de Biologia Tropical 39: 207-214.

Horres, R; Zizka, G.; Kahl, G. \& Weising, K. 2000. Molecular phylogenetics of Bromeliaceae: evidence from $\operatorname{trn} \mathrm{L}$ (UAA) intron sequences of the chloroplast genome. Plant Biology 2: 306-315.

Johansen, D.A. 1940. Plant microtechnique. New York, MacGraw-Hill Book Company.

Kraus, J.E. \& Arduin, M. 1997. Manual básico de métodos em morfologia vegetal. Seropédica, Edur.

Krauss, B.H. 1949. Anatomy of the vegetative organs of the Pineapple, Ananas comosus (L.) Merr. II - The leaf. Botanical Gazette 110: 333-404.

Linder, P.L. \& Rudall, P.J. 2005. Evolutionary History of Poales. Annual Review of Ecology and Evolution Systematic 36: 107-124.

Martin, C.E. 1994. Physiological Ecology of the Bromeliaceae. The Botanical Review 60: 1-82.

Mauseth, J.D. 1988. Planty anatomy. California, Benjamin/ Cummings Publishing Company.

Medina, E. 1974. Dark $\mathrm{CO}_{2}$ fixation, habitat preference and evolution within the Bromeliaceae. Evolution 28: 677-686.

Pita, P.B. 1997. Estudo anatômico dos órgãos vegetativos de Dyckia Schultz f. e Encholirium Mart ex Schultz f. (Bromeliaceae) da Serra do Cipó - MG. Dissertação de Mestrado. Instituto de Biociências, Universidade de São Paulo, SP.

Proença, S.L. \& Sajo, M.G. 2004. Estrutura foliar de espécies de Aechmea Ruiz \& Pav. (Bromeliaceae) do Estado de São Paulo. Acta Botanica Brasilica 18: 319-331.

Prychid, C.J. \& Rudall, P.J. 1999. Calcium oxalate crystals in monocotyledons: a review of their structure and systematics. Annals of Botany 84: 725-739.

Pyykkö, M. 1966. The leaf anatomy of East Patagonian xeromorphic plants. Annales Botanici Fennici 3: 453-622.

Ribeiro, J.F \& Walter, B.M.T. 1998. Fitosionomias do bioma cerrado. Pp. 89-166. In: S.M. Sano \& S.P. Almeida (coords.). Cerrado: ambiente e flora. Planaltina, EMBRAPA-CPAC.

Robinson, H. 1969. A monograph on foliar anatomy of the genera Connelia, Cottendorfia and Navia (Bromeliaceae). Smithsonian Contributions of Botany 2: 1-41.
Sajo, M.G.; Machado, S.R. \& Carmello-Guerreiro, S.M. 1998. Aspectos estruturais de folhas de bromélias e suas implicações no agrupamento de espécies. Pp. 102-111. In: M.V. Pereira (ed.). Bromélias da Mata Atlântica: Canistropsis. Rio de Janeiro, Salamandra Consultoria Editorial Ltda.

Sass, J.E. 1951. Botanical microtechnique. Ioawa, State College Press.

Scatena, V.L. \& Segecin, S. 2005. Anatomia foliar de Tillandsia L. (Bromeliaceae) dos Campos Gerais, Paraná, Brasil. Revista Brasileira de Botânica 28: 635-649.

Smith, L.B. \& Downs, R.J. 1974. Pitcairnioideae (Bromeliaceae). Flora Neotropica, Monograph 14: 1-662.

Smith, L.B. \& Downs, R.J. 1977. Tillandsioideae (Bromeliaceae). Flora Neotropica, Monograph 14: 663-1492.

Smith, L.B. \& Downs, R.J. 1979. Bromelioideae (Bromeliaceae). Flora Neotropica, Monograph 14: 1493-2142.

Smith, L.B. \& Till, W. 1998. Bromeliaceae. Pp. 74-99. In: K. Kubitzki (ed.). The Families and Genera of Vascular Plants IV. New York, Springer.

Sousa, G.M.; Estelita, M.E.M. \& Wanderley, M.G.L. 2005. Anatomia foliar de espécies brasileiras de Aechmea subg. Chevaliera (Gaudich. ex Beer) Baker, Bromelioideae Bromeliaceae. Revista Brasileira de Botânica 28: 603-613.

Souza, R.C.O.S. \& Neves, L.J. 1996. Leaf anatomy of four Tillandsia species. Bromélia 3: 28-39.

Strehl, T. 1983. Forma, distribuição e flexibilidade dos tricomas foliares usados na filogenia de Bromeliáceas. Iheringia, Série Botânica 31: 105-119.

Sunell, L.A. \& Healey, P.L. 1979. Distribution of calcium oxalate crystal idioblasts in corms of taro (Colocasia esculenta). American Journal of Botany 66: 1029-1032.

Tomlinson, P.B. 1969. Comelinales - Zingiberales. Pp. 193-294. In: C.R. Metcalfe (ed.). Anatomy of the monocotyledons: III. Oxford, Claredon Press.

Varadarajan, G.S. \& Gilmartin, A.J. 1987. Foliar Scales of the subfamily Pitcairnioideae (Bromeliaceae). Systematic Botany 12: 562-571.

Yoshida, S.; Ohnishi, Y. \& Kitagishi, K. 1962. Histochemistry of silicon in rice plant. III. The presence of cuticle-silica double layer in the epidermal tissue. Soil Science And Plant Nutrition 8: 1-5. 